\title{
"Mapping-with": The Politics of (Counter-)classification in OpenStreetMap
}

\begin{abstract}
In this paper I consider how debates in critical cartography about the classificatory and calculative logics of the map might be renegotiated through the concepts of "making-kin," "sympoesis," and the chthonic. Between Haraway's (2014) Staying With The Trouble and Foucault's (2002) writings on mathesis and taxinomia in The Order of Things, I argue that a more situated understanding of mapping - as an entanglement between people, tools, landscapes, cultures — might realise a more open, and more attentive, way of mapping. I return to the popular case study, OpenStreetMap, to excavate how the use and misuse of taxonomic and mathematical logics through its collaborative and amateur affordabilities shed light on different ways of sorting-with the world. I argue that, in the unexpected emergence of proposed classifications (and despite the disciplining power of cartographic discourses), roots of a new and more inclusive cartography linger in the archive, waiting to be fertilised.
\end{abstract}

KEYWORDS: mapping; critical cartography; digital geography; counter-mapping

\section{THE TROUBLE OF MAPPING}

In the introduction to Staying With the Trouble, Donna Haraway (2016) asks us to "make kin" in turbulent times. As Western structures of knowledge and space are undergoing a global liquefaction, neither technological panaceas, apocalyptic imaginaries, nor critical fatalism are privileges afforded to those who have something at stake in our combined futures. "The task," she argues, "is to make kin in lines of inventive connection as a practice of learning to live and die well with each other in a thick present" (Haraway 2016, 1). "Making kin" requires us to stay with the trouble, to map with, rather than against, complexity and paradox, and to understand ourselves as "mortal critters entwined in myriad unfinished configurations of places, times, matters, meanings" (Haraway 2016, 1). This approach requires a timely re-encounter with the study and practice of cartography as it becomes increasingly awash with critical debate over the production of spatial knowledge (Elwood and Leszczynski 2013).

As such, this short article is an attempt to stay with what Matt Wilson (2017) has called "the trouble of the map," or, as I prefer, the "trouble of mapping." While the "trouble of the map" takes up the politics and economies of representations-criticality, digitality, movement, attention, and quantification - staying with the trouble of mapping requires us to return the murkiness of representing as an active engagement with, in, and of the world. There is a crucial distinction here: if the trouble of the map might be understood as the trouble of the sign, the trouble of mapping is the trouble of arranging, translating, and negotiating, as mappings draw knowledge into, through, and from the world. Moving away from the object (the map) or the subject (the mapper), we might instead follow a path that Massey (2005) has previously called "coformation," and which Haraway (2014) terms "sympoesis." This radical framework of "sympoesis" emphasises the politics, but also the potential, of "becoming-with" other processes, animals, people, materials, concepts, and matter in what she calls a "compost."

Thus, in this article, to stay with the trouble of mapping is to resituate cartographic practices on the disturbed ground of ongoing debates (Leszczynski 2009), and to re-embrace the tools of cartographic classification and calculation that 
we find there. Hence, the trouble of mapping is to be found in the trouble of arranging relations between thingswhether physical or social objects, landforms, lines on a page, or pixels on a screen. In terms of mapping, this means reconnecting and reinvigorating old representational alliances with lines, numbers, and names, while mapping-with new digital capabilities and tools. Often, these arrangements are seen as "god tricks" (Haraway 1998), where powerful mappers are cast as puppeteers above the stage, arranging the limbs of the world into strange and absolute cartographic choreographies. Counter-mappers turn the tools of cartography towards uprooting this power, realising the potential of mapmaking for political resistance (Peluso 1995) through counter-mapping (Counter Cartographies Collective 2012), participatory mapping, and volunteered geographic information (VGI; Elwood 2008). Yet, critical cartographers have suggested that cartographic tools - the calculative and classificatory logics underpinning the scientific authority of the mapare interminably and politically flawed, drawn as they are from an Enlightenment desire for absolute objectivity and universality. Both the stances of the counter-mappers and the critical cartographers have their drawbacks-between necessary evils and stuck-in-the-mud constructivismand so the maps with which we live are at once emancipating and confining. Rather than trying to escape this conflict or constantly revisit, as Leszczynski (2009) writes, an ontological impasse, I argue here that perhaps this trouble-as compost between people, environments, and meanings - might instead be fertile ground for rethinking what counter-mapping, and digital mapping more generally, could be.

By unpacking the theoretical work of Donna Haraway, I also argue for a return to the critical potential of feminist science and technology studies within cartography, signposted by the ongoing work of feminist and queer geographers such as Pavlovskaya (2018), Giesking (2018), Leszczynski and Elwood (2015), and Kwan (2007)—not simply as a tool for a feminist critique, but a way of remaking worlds, rather than just remaking maps. That mapping has troubles is not a new argument: significant empirical research has been undertaken documenting and advancing our understanding of the technopositional (Wilson 2017), tacit (McHaffie 2002), institutionalised (Gekker 2016), and politicised (Thatcher and Imaoka 2018) practices undertaken by cartographers, educators, and geographic information scientists. Furthermore, that the politics of mappings are based in situated knowledges (Wilmott
2016), embodied (Lin 2006), vernacular (Gerlach 2015), and taken up in the everyday (Del Casino and Hanna 2005) is also well documented within cartographic research. The tension between the role of classification and classificatory logics embedded in top-down GIS practices and the (counter-)classifications (re)produced by publics has also been described as a complicated translation between scientific and lived knowledges which, through mapping, challenge the assumptions often made invisible in cartographic processes (Cidell 2008). What I seek to do in this article is make a theoretical argument that trouble provides us with alternative foundations-diffractive fixpoints, if you will-for counter-mapping, and that the potential of these for what O'Sullivan $(2006,783)$ has called a "critically informed GIS" is powerful. This is supported by Haraway's arguments about feminist entanglements with technology since A Manifesto for Cyborgs (1985), which present an ongoing campaign to build "ironic political myth[s]" (65), to make "an argument for pleasure in the confusion of boundaries and for responsibility in their construction" (66), beyond a positivist/post-structuralist dichotomy. In the context of cartographic science, this means not only to recognising and critiquing mapping's troubles, but to embrace and take pleasure in cartographic confusions as productive tools to find different ways of making worlds—scientifically, socially or otherwise.

To do this, I return to a classic question in the digital cartography canon: the case study of OpenStreetMap (OSM). Understanding OSM as sympoetic is to see a muddle of alliances across material-semiotic landscapes, rather than a battlefield or a poisoned chalice. While some scholars have lauded OSM for its role in producing a democratising "neogeography" (Goodchild 2009), others have been cautious of the power which it affords, inscribes, and reinscribes (Haklay 2013). Yet, even though the politics of the tools of OSM are embedded in the necessities of scientific communication-specifically, classification - their enactment is deeply political, dependant on translations between the semiotic and the material (Glasze and Perkins 2015), as well as the ethical (Gerlach 2010). Thus, where some politics in OSM might be powerfully fixed (Perkins 2014), others might also mobilise at the margins and in the fragments. The task before us, then-to stay with the trouble of mapping - is wilfully optimistic. "Mapping-with" is to understand cartography as deeply political, but also not necessarily weighed down by its power. Rather, mappings are inventive arrangements between digital tools, social forces and diverse landscapes. Staying with the trouble of 
mapping, then, is negotiate the ethics of rendering and arranging between signs and senses, marks and matter, and to recognise that we can and do have some power over our cartographic entanglements.

\section{MAKING KIN WITH MATHESIS AND TAXINOMIA}

LIKE MOST (OR PERHAPS ALL) digital mappings, OpenStreetMap is founded on calculative and classificatory logics (Crampton 2011)—or, in Foucault's (2002) terms, mathesis (mathematics) and taxinomia (taxonomy). These twin logics are crucial cartographic arrangers, producing nests of order and hierarchies at the level of representation and scientific abstraction. As Foucault states:

Mathesis is a science of equalities, and therefore of attributions and judgements; it is the science of truth. Taxinomia, on the other hand, treats of identities and differences; it is the science of articulations and classifications; it is the knowledge of beings. (Foucault 2002, 81)

Mathesis and taxinomia are dangerous ideas-partly because they are old ideas-but mostly because of the way in which they have been purposed in colonial and capitalist agendas to undermine situated knowledges or erase them entirely. The trouble with mathesis and taxinomia is that within them they contain the desire to eliminate contradictions and paradoxes-to become a universal system of knowledge, based on numbers or classifications, somewhere between philosophy and empiricism. However, while mathesis occupies a theoretical realm of pure, objective mathematics, for Foucault (2002), it is in taxinomia that the abstraction of mathematics becomes applied to the material or lived world. Thus, where mathesis asks how, taxinomia asks what. Taxinomia-the process of classifying-orders objects, ideas, and lives into discrete objects and hierarchies. Sorting though, gathering, and tying together, the process of taxonimising inscribes what kind of object or being is coherent, repetitive, and regular enough - both on a material and a conceptual plane-to exist. At what point does a street become a path or a road, and what colour should it be on the map? These questions of classification are at the crux of mapping. While capitalist-colonial, and, increasingly, digital cartographic enterprises have tended towards cohering the world into generalisable systems of (sometimes worldwide) classificatory representation (Ryan 1996), indeterminate landscapes do not always adhere well to the categories imposed upon them. With the increased interest in more participatory forms of mapping (such as "neo-geography," participatory GIS, counter-mapping, etc.) and the cartographic tools used to enable them (such as OSM) these categories become further muddied. In part, this is because the cartographic gaze - which Wilson (2011) describes as a triad between perspective, projection, and accuracy-is now composed of multiple experiences, from multiple mappers who map with multiple purposes in mind.

Much like the relationship between ghosts and hauntings (Gordon 2008), the map is merely the sign that a mapping has taken place. Mappings are material-discursive (Barad 2007): matter and meaning entangled; form and function hybridised. As cartographic (infra)structures become more complex, and mappings are mapped-with more and different people, tools, landscapes, and knowledges, more oddkin join the muddle. The kinships formed by oddkin are unexpected collaborations, required in order to exist, and which accord mutual responsibility for both how these entanglements occur, and to whom they are accountable: "We become-with each other or not at all" (Haraway 2016, 4). In digital entanglements, oddkinships become more complicated: objects and subjects are muddied as agency is dispersed across algorithms, machines and IT critters (Haraway 2016, 32), and questions about who the mapmakers might be are transformed into questions about human-technology relations and cyborg cartographies. Here, in OSM, the politics of mapping refracts in unexpected ways, deep in the chthonic vaults of data, instruction manuals, wikis, proposals for features, redrafts, expansions, and updates (Perkins 2014). OpenStreetMap has over one million contributors. Through this single platform, millions of lives and localities come into contact, creating frictions between the universal classificatory system of OSM, the more particular knowledges of desk-based mappers working with satellite imagery, and the specific situated knowledges of the mappers who have traversed or live in the landscape. Along with computers, cameras, images, GPS devices, and landscapes, these sets of oddkin enter into negotiation over the terms of mapping through what should and should not be expressed on the map (features) using an ever-changing collection of "tags." 
At the time of this writing in 2019, there were at least 3,048 tag descriptions in OpenStreetMap (Figure 1). A brief overview of the tag set for what OSM calls highways reveals a surprising number of distinct classes, including motorways, trunks, primary roads, service roads, pedestrian highways, raceways, and even bridleways - with clear rules and descriptions for each. How - and where-these tags should be applied by individual mappers is outlined in exacting detail. For instance, the highway=motorway tag specifically delineates:

a restricted access major divided highway, normally with 2 or more running lanes plus emergency hard shoulder. Equivalent to the Freeway, Autobahn, etc. (OpenStreetMap Wiki, n.d.)

Here, the specificity of the classification rests on the highway's controlled access and, generally, its size. Of course, while this gives a general impression of how we might conceptualise and apply highway=motorway to controlled-access highways across a variety of landscapes (i.e., between the USA, Germany, Australia, and Canada), there are also some important cultural, social, economic, historical, and indeed, governmental distinctions about how this class of roads might be integrated into their specific situated locales-as Merriman's (2007) cultural history of the M1 in the United Kingdom suggests. Similarly, highway=livingstreet (a space that prioritises pedestrian or cyclist activity) has multiple iterations across languages and cultures as a "shared space," "home zone," "zone residentielle," etc. The original Dutch term woonerf becomes translated and reified into English as "living street," but in doing so, the elements of cultural specificity in the Dutch context are erased from the map, and so too is the lineage of the turn away from automobile spaces towards residential shared zones (and their history in Dutch urban design, canal networks, and architecture; see Guttenberg 1982).

\begin{tabular}{|c|c|c|}
\hline \multicolumn{3}{|c|}{ Pages in category "Tag descriptions" } \\
\hline \multirow{2}{*}{\multicolumn{3}{|c|}{$\begin{array}{l}\text { The following } 200 \text { pages are in this category, out of } 3,048 \text { total. } \\
\text { (previous page) (next page) }\end{array}$}} \\
\hline & & \\
\hline & - Tag:aeroway=taxilane & - Tag:amenity=crematorium \\
\hline A & - Tag:aeroway=taxiway & - Tag:amenity=crucifix \\
\hline - Tag:abandoned=yes & - Tag:aeroway=terminal & - Tag:amenity=crypt \\
\hline - Tag:abandoned:amenity=prison & - Tag:aeroway=windsock & - Tag:amenity=customs \\
\hline - Tag:abandoned:amenity=prison camp & - Tag:airmark=beacon & - Tag:amenity=dancing school \\
\hline - Tag:access=customers & - Tag:ale supply=limited & - Tag:amenity=dead pub \\
\hline - Tag:access=designated & - Tag:allotments=plot & - Tag:amenity=dentist \\
\hline - Tag:access=exclusion zone & - Tag:amenity=administration & - Tag:amenity=device charging station \\
\hline - Tag:access=license & - Tag:amenity=advertising & - Tag:amenity=disused \\
\hline - Tag:access=no & - Tag:amenity=alm & - Tag:amenity=dive centre \\
\hline - Tag:access=official & - Tag:amenity=animal boarding & - Tag:amenity=doctors \\
\hline - Tag:access=private & - Tag:amenity=animal breeding & - Tag:amenity=dog bin \\
\hline - Tag:access=restricted & - Tag:amenity=animal shelter & - Proposed features/Dog Poop Area \\
\hline - Tag:actuator=electric motor & - Tag:amenity=animal training & - Tag:amenity=dog toilet \\
\hline - Tag:actuator=hydraulic cylinder & - Tag:amenity=architect office & - Tag:amenity=dog waste bin \\
\hline • Tag:actuator=manual & - Tag:amenity=archive & - Tag:amenity=dojo \\
\hline - Tag:actuator=pneumatic cylinder & - Tag:amenity=arts centre & - Tag:amenity=dressing room \\
\hline - Tag:admin level=2 & - Tag:amenity=artwork & - Tag:amenity=drinking water \\
\hline - Tag:advertising=billboard & - Tag:amenity=atm & - Tag:amenity=driver training \\
\hline - Tag:advertising=board & - Tag:amenity=audiologist & - Tag:amenity=driving school \\
\hline - Tag:advertising=column & - Tag:amenity=baby hatch & - Tag:amenity=dryer \\
\hline • Tag:advertising=flag & - Tag:amenity=baking oven & - Tag:amenity=education \\
\hline - Tag:advertising=poster box & - Tag:amenity=bank & - Tag:amenity=embassy \\
\hline - Tag:advertising=screen & - Tag:amenity=bar & - Tag:amenity=emergency phone \\
\hline - Tag:advertising=sculpture & - Tag:amenity=bbq & - Tag:amenity=events venue \\
\hline - Tag:advertising=sign & - Proposed features/Bell & - Tag:amenity=ev charging \\
\hline - Tag:advertising=tarp & - Tag:amenity=bench & - Tag:amenity=exhibition centre \\
\hline - Tag:advertising=totem & - Tag:amenity=bicycle parking & - Tag:amenity=fast food \\
\hline - Tag:advertising=wall painting & - Tag:amenity=bicycle rental & - Tag:amenity=feeding place \\
\hline - Tag:aerialway=cable car & - Tag:amenity=bicycle repair station & - Tag:amenity=ferry terminal \\
\hline - Tag:aerialway=canopy & - Tag:amenity=bicycle trailer sharing & - Tag:amenity=festival grounds \\
\hline - Tag:aerialway=chair lift & - Tag:amenity=biergarten & - Tag:amenity=financial advice \\
\hline - Tag:aerialway=drag lift & - User:Mackerski/Tag:amenity=bikeshed & - Tag:amenity=fire hydrant \\
\hline - Tag:aerialway=gondola & - Tag:amenity=bird bath & - Tag:amenity=fire station \\
\hline - Tag:aerialway=goods & - Tag:amenity=boat rental & - Tag:amenity=fish spa \\
\hline - Tag:aerialway=j-bar & - Tag:amenity=boat sharing & - Tag:amenity=food court \\
\hline - Tag:aerialway=magic carpet & - Tag:amenity=boat storage & - Tag:amenity=fountain \\
\hline - Tag:aerialway=mixed lift & - Tag:amenity=brothel & - Tag:amenity=fridge \\
\hline - Tag:aerialway=platter & - Tag:amenity=bts & - Tag:amenity=fuel \\
\hline - Tag:aerialway=pylon & - Tag:amenity=bureau de change & - Tag:amenity=gambling \\
\hline - Tag:aerialway=rope tow & - Tac:amenitv=hus station & - Tan:amenitv=aame feedina \\
\hline
\end{tabular}

Figure 1. A sample of tag descriptions for the letter "A" from the OSM wiki, 2019. 
The argument that cartography is a homogenising force states that, when situated knowledges are stretched into platforms like OSM through mathesis and taxinomia, the bespoke and the unique (like the woonerf) are gradually erased (Pickles 2004). As global mappings with global datums emerge, knowledges that are exterior to popular or dominant ways of thinking become subjugated, eviscerated, or suppressed (Foucault 2003). Hence, universality comes to its position as a dominant, hegemonic desire. The critics of the truly emancipatory power of participatory GIS make their arguments here (Perkins 2014). Certainly, the opening up of mapping to the amateur, the public, the citizen, and the counter-mapper through participatory and collaborative projects has, to some degree, challenged more "traditional" cartographic authority over spatial knowledges (Liu and Palen 2010). At the same time, it is also true that these new, more open, cartographic tools and platforms also demand an adherence to their own pre-determined rules and hierarchies of classification-places, features, objects, attributes, tags, nodes, etc.- that are dominated by the collaborators' most common needs, perceived universalities, and cartographic traditions (Haklay 2013).

At the same time, situated knowledges are not entirely erased from the process of mapping, even where they may disappear from the map. In the friction between global systems of classification and local contexts (with their historical, geographical, and cultural specificities), the trouble of mapping percolates in both the drawing of the map and the reading of the map. In the first instance, a two lane country road linking two towns, with no verge and a moderate speed limit, might be translated into either highway=primary or highway=secondary, depending on the population of the country, the number of cars which drive along it, how well it is known, or how many other places it travels through. It might also depend on the width of the road (for someone who has visited it) or how significant it appears on a satellite image (for those who map from afar). For the second instance, how a map reader understands highway=primary or highway=secondary will also depend on their local experiences. Roads with narrow hedgerows typical of Europe are vastly different to dust tracks in Australia, though both might be highway=secondary roads. This matters: choice of transport, the impact of weather events, the length of journey, the difficulty of the drive, or how crowded the road might be are intensely local factors which shape a journey, even if they are not encompassed within this particular system of classification. Here, the reading of a map is as troubled as its making.

This is not to say that "trouble" is troubling. One way to view mapping is as hegemonic - a top-down or majoritarian enforcement of certain cartographic gazes over others through classification (see, for instance, Ryan 1996). But this viewpoint is necessarily limiting, based on critique of the fundamental principles of representation. As Borges (1964) wrote, there cannot be an exact science with rules for every possible eventuality, and so, some level of interpretation is always necessary in the act of cartographic representation. I rather view the concept of trouble as opening up possibilities, where the ambiguities of classification might make alternative spaces of action, rather than destroying them. These spaces could be made through specifically political efforts-such as counter-mapping, Indigenous mapping, participatory mapping and GIS, or propaganda mapping. But they also are made incidentally in the process of all mapping-even as we have seen in classifying and tagging highways on OpenStreetMap. This is evident, as Leszczynski and Elwood (2015) describe, when the participatory and the hegemonic come into contact. In the trouble of mapping, we must choose: whose language, whose culture, and whose discourse should we use? Whose experiences, what objects, or what moments count hegemonically, so they may be countered? Then, crucially, we must ask what does not count? Who do we forget, or what do we hide, ignore, secret away, dull, or mask-how do you counter that which is absent or invisible, and what are the lines across which we argue?

This kind of questioning, I argue, is a space brimming with "speculative fabrication" (Haraway 2016, 134). In this space, we might explore different ways of countering, beyond simply providing new tags for existing classifications, towards a sustained experimental and critical engagement with the process of classifying itself. This space requires reconciliation between the past of mapping and its future, "mapping-with" classification, rather than against it. Thus, the question we can return to is if it is possible to embrace the process of classification and see if classificatory practices can work with, rather than against, a menagerie of voices-heterogeneity rather than universality? In the rest of this article, then, I will work to reposition our critical focus towards a more sustained critique of the desire (and indeed, requirement) for universalism (universalis). Is it 
possible to pay heed to the ephemeral, contradictory, transient, and local on a global platform like OSM-to "make kin" with classification and develop different taxonomic systems based on situated knowledges, partial descriptions and local environments? Here, a different kind of politics emerges-where the architectures of calculation and classification do not have to be prisons, but instead may form kinships with technologies, people, and landscapes as heralds of possibilities and champions of the vernacular.

\section{TROUBLE AND HOP GARDENS IN}

I LIKE TO READ the proposed features on the OpenStreetMap wiki. A junkyard of cultural treasures, they make a very different map to the more official one we see and to which we contribute. When Haraway (2007) writes of the cthulhucene, she is describing a way of understanding the world as "tentacular." Rather than hierarchical, or historical structures of knowledge, the tentacular has multiplicitous zones of contact between ideas, critters, plants, and other oddkin, which loop outwards and inwards, around and through. Furthermore, as Haraway suggests, "the tentacular are also nets and networks, IT critters, in and out of clouds" (Haraway 2007, 32). Across the OSM wiki, different entries, edits, and comments compost the tentacular networks of the formulations, discussions, negotiations, and (re)tracings into a co-production of the cartographic surface of OSM. Each classification becomes manifest through code, collaborations, and the different kinds of considerations which become abundant when multiple lives, technologies, landscapes, and languages connect through tentacular contact zones.

In theory, platforms like OpenStreetMap can refract these multiplicities of experiences and stories made by oddkin in our complicated world. The magnification of thousands of landscapes, features, habits, and stories should point to the heterogeneity of space-as Massey (2005) sees it-and make trouble, rather than resolve it. Ideally:

OpenStreetMap's free tagging system allows the map to include an unlimited number of attributes describing each feature. The community agrees on certain key and value combinations for the most commonly used tags, which act as informal standards. However, users can create new tags to improve the style of the map or to support analyses that rely on previously unmapped attributes of the features. (OpenStreetMap Wiki, n.d.)

\section{THE CTHULHU-OSM}

OSM does not have the same material representational limits as physical maps. Every point on a paper map, atlas, or globe can only be defined by as many inscriptions, carvings, or ink marks that can fit on its immutable surface (Lammes 2017). Since OSM is not limited by the materiality of paper, multiple mutable digital inscriptions might overlay the same point ad infinitum, limited by server rather than canvas space. It might be possible-in theory and with a toggle function - to represent a road as both highway=primary and highway=secondary (although it might not be very useful). Furthermore, as has been widely documented, digital maps like Google are easily able to adjust toponymic and border information to mirror the social and cultural contexts of the viewer (Gekker 2016). Thus, in theory, the digital map may also house and display information that is not only contradictory, but occupies fundamentally different systems of classification (highway=primary, surface=bumpy, landscape=haunt ed). The development of feature sets in OpenStreetMap is managed through a rigorous, but sporadically applied, peer-review process of discussion, questioning, and voting. Sometimes a feature makes it onto the list (such as amenity=grit_bin), others are rejected (amenity=skyhook), others are cancelled (amenity=bicycle_tube_automat) and some are abandoned (amenity=husainiya).

These multivocal mappings linger in the archives of the OSM wiki as snapshots of the heterogeneity of lives, landscapes, practices, services, and cultures that exist across the world. For instance, amenity=grit_bin is only needed for climates that are cold and icy, where the roads and footpaths may need to be gritted. This brings to the fore Haraway's use of "chthonic" - or Chthonic Ones-as a way of describing that which is earthly, embedded in terra and terrain. From the depths, they emerge like gorgons, but the chthonic ones are allies too, even though they disrupt harmony and the smooth façade of universality. The chthonic ones, in the case of OSM, emerge in the entanglements of mapping with deep space and deep time. Put simply, the features proposed on OSM are embedded both 
in contemporary geographies and historical mapping practices. For instance, in one of my favourite feature proposals (Figure 2), I learn that in Czechia some older cadastral maps mark where hops-primarily used for beer-are grown. As large fields featuring tall poles which protrude into the sky, landuse=hop_garden kinships are apparently useful for navigation due to their plant-human-technology-cartography sympoesis.

\section{hop_garden \\ Status: Abandoned (inactive) \\ Proposed by: chrabros

$\begin{array}{ll}\text { Tagging: } & \text { landuse=hop_garden } \\ \text { Applies to: } & \text { area } \\ \text { Definition: } & \text { A piece of farm land where hops are grown. } \\ \text { Rendered as: A green-brown area with repeating symbol \$ } \\ \text { Drafted on: } 2014-03-05 \\ \text { RFC start: } 2014-03-05\end{array}$

Figure 2. Status: abandoned. "landuse=hop_garden" by chrabros (wiki.openstreetmap.org/wiki/Proposed_features/Hop_garden).

The proposer of this particular feature, OSM user "chrabros," writes that they (whoever they may be) are undertaking a large import of Czech cadastre data into OSM, which includes hop gardens as a feature. As a consequence, they would like to set up some classificatory compatibility between the two mapping systems. Precisely how this classificatory compatibility might emerge becomes the substantive body of the proposal's rationale, with considerable consideration of other ways of classifying the hop gardens, including how to add hops as a specific crop to different landuse tags: landuse $=$ farmland $+c r o p=h o p$; landuse $=$ or char $d+c r o p=h o p$. They additionally propose that these zones appear on the OSM surface as "a greenbrown area with repeating symbol \$.”

The discussion by chrabros raises a principal set of motivations for the proposal: hop fields are extremely stable and are not usually adapted for any other kinds of agricultural production (such as wheat or canola); as culturally significant spaces of production in Czechia, they are distinct from other kinds of agriculture (such as the general "farmland" or the specific "orchard"); and, given the approval of features such as landuse=vineyard, why should hop fields be less distinguished than other agricultural land uses? The concept of the chthonic-within the chthulu-OSM-gives us a different way of understanding OSM, and the role that the earthly (i.e., terrains like hop gardens, practices like farming, or people like chrabros) plays in the sympoesis of open mapping platforms. These are cultural, as well as cartographic, commentaries about scaling between situated and specific knowledges and practices, and broader, global, cartographic categorisation. They are also critiques of uneven attribution of features across different social, cultural, and physical geographies, national boundaries, languages, etc., that emerge throughout the conversation on OSM:

"Czech cadastre differentiates between farm land and hop garden so why should not we?"

\begin{abstract}
"landuse=orchard, landuse=vineyard, landuse=plant_nursery $-\ldots$ if these deserve their own tags then hop garden should have it too. They are not that much different."
\end{abstract}

And,

"It is named 'chmelnice' in Czech, 'Hopfengarten' in German and in Egnlish [sic] several terms are used. But I believe, and hope that someone approves it, that 'hop garden' is a proper UK English term for this feature."

These explanations engage a cultural politics of the different global value attributed to wine production through vineyards, against beer produced through hop fields. They also point precisely to the trouble of mapping-specifically of translating and making equivalences between places, maps, and cultures - and chart how debate moves towards consensus (that is, approving the feature).

Across terrain and maps, another rationale points directly to a curious relationship between material stability and cartographic stability. Orchards, farmlands, and hop fields appear differently in situ. Orchards, as rows of trees in grass, or farmlands, as variable crop fields, chabros argues, are not as continuous and consistent as hop fields, which have a specific physical earthly appearance. When wandering through rural farmlands, being able to correlate the specific appearance of different agricultural crops with map data could be extremely useful. With tall poles that rise into the air, chabros makes a strong claim that hop fields are excellent landscape tools-allies even-for 
navigation and orientation, and so are worthy of being included as their own category on the map.

landuse=hop_garden ended up "Abandoned (inactive)." It's difficult for a lurker in the chthonic like me to know why chabros gave up in the end. But the subsequent discussion by other users gives us some idea of the complexities of working between classificatory logics and situated knowledges. This discussion expands the comparison between hop fields and vineyards to rice fields (which don't change, landuse $=$ farm + crop $=$ rice) and eggplant fields (landuse $=$ farm + crop=vegetable). The regional specificity of hop gardens is a major stumbling block: user johnw writes that "I've never seen (or up until now heard of) a hops [sic] garden ... the other landuses seem pretty universal and well known, while hops garden (or eggplant trellis) seems to me region specific AND easily represented by other tags." At the same time, while hops production is often localised to specific geographies, it is still found across the world-from China, to the US, Europe, South America, Africa, and Australia, depending on the climate. These conversations reveal a careful negotiation between the politics of attending to perceived regional specificity but not creating a plethora of feature tags. This is a discussion about what mapping means and what classifications are important to different people: a mapping muddle between general and local knowledge, between the universal and the earthly.
Returning to Haraway, and the framework of sympoesis or "mapping-with," it sometimes seems as if rather than embracing the mess inherent in working with (agri)cultures, landscapes, and local-global knowledge translation, the general idea is to clean it up. In terms of OSM, this means fewer classifications, simpler categories, and the hegemonic reassertion of assumed universalities regardless of their basis in everyday practices. The issue here is not the practice of taxonomy itself, but the hegemonic structures of power/knowledge that determine what is worthy of its own classification. landuse=hop_garden challenges those structures. This is a particular kind of kinship between bio-geographies, cultures, and cartographies, which, though specific, is extremely pertinent to the process of mapping itself, and also underscores the importance of platforms like OSM being able to "speak to," or "map-with" local geographical practices, cultures and cartographies. It redefines how we might cartographically understand continuity according to the durability of specific cultural practices like hop growing, rather than the breadth and commonality of spatial distributions, like farming more generally. It also speaks to the attachments to local material landscapes, and how these become embedded in cartographic traditions and situated navigational practices between plants, technologies, landscapes, and people-from the height of poles in hop gardens to the patina of vineyards.

\section{TRICKING THE GODS: PARTIAL PERSPECTIVES AND DIGITAL KINSHIPS}

Haraway describes the gaze of the scientist, who stares from an objective nowhere through a lens or screen toward the world, as a "god trick" (Haraway 1988, 581). This god trick requires two components to function: firstly, vision - the act of seeing or staring, especially through technological means such as a camera or microscope; and secondly, the assumption of objectivity - that such a process could approach a total objectivity, or neutral or unbiased manner of getting the sum of the world. While it is arguable that most maps fulfil, in part, the function of this god trick, in OSM-with its chthonic and tentacular systems of participatory negotiation between people, technologies, terrains, and cultures-it is possible to see how the myth of total objectivity is somewhat farther away. Staring back at the god trick are the situated knowledges of mappers new and old, who make their own offerings to the datasets, in new places, taxonomies, and systems-knowledge from the ground up.

This is particularly evident in the changeset archives, where traces can be found of mappers attempting to shape different possibilities within classificatory logics. Here, points, lines, and polygons are reoriented towards lived earthly experiences, moulding while resisting OSM's cartographic logics. For instance, the residues of nana22's village lingers in the map, even though they closed the changeset over a year ago (Figure 3).

Marking one's home-as nana22 does-is perhaps an unsurprising act on an open map. It is, perhaps, also a strike against the god trick, a situated mapping from the ground earth rather than the satellite eye. "This is a public map," Diseret reminds us, "don't put your house." A discussion 
emerges in mapping-with across spaces and experiences, with other people, the oddkin of villages and aerial imagery, social (but not essential) rules of universal taxonomic practice, and the slippages of mapping from afar and from nearby.

What is the impulse, then, to sort through the trouble, and order alliances into formations that are more universal than emancipatory? Either as a cartographic impulse to order the world, or a counter-mapping impulse to re-order it, as thousands of databases are fertilised by alliances between specific landscapes, cultures, practices, critters, and people, the only certainty - the only stable rock, the only predictable refraction-is heterogeneity. This is where Haraway (1988) might chime in again and speak of the privilege of partial knowledge or perspective. Partial knowledges, she argues, are objective because they are

\section{Changeset: 55360758}

c'est mon village

Closed over 1 year ago by nana22

\section{Tags}

\begin{tabular}{|l|l|}
\hline changesets_count & 1 \\
\hline created_by & iD 2.5 .1 \\
\hline host & $\begin{array}{l}\text { http://www.openstreet } \\
\text { map.org/edit }\end{array}$ \\
\hline imagery_used & Bing aerial imagery \\
\hline locale & fr \\
\hline review_requested & yes \\
\hline
\end{tabular}

\section{Discussion}

\section{Comment from Diseret over 1 year ago}

C'est une carte publique, $n$ 'indiquez pas votre maison.

Figure 3. "c'est mon village": "this is my village," by nana22. finite and situated, with less interest in creating distances between subjects and objects than resolving them as inextricably intertwined. In the context of OSM, partial perspectives underscore the boundaries of our gaze and although the eye of the satellite-cartographer-camera might float above the world, our own positionality limits what we can see. To embrace a partial perspective means that we become grounded in our own responsibility towards who, what, where, and how we map.

There is no real rule that means that we cannot speak of hop_gardens or villages. If we can speak of these, then, in the dust of democratic mapping, oddkin-for instance, sacred sites or Aboriginal lands-appear to remind us of our political problems. This example makes an incidental case for the translation of local knowledges into a broader mapping platform that could, in theory, be defined by heterogeneity and diversity:

we are all members of many communities of practice. Multiplicity is in play with standardizations, and no one is standard or ill fitted in all communities of practice. (Haraway 2018, 38)

This would be a "mapping-with," rather than a "mapping-against." In doing so, it could also make room for speculative fabrications on how specific landscapes might engage a different, but possibly more effective, politics of mapping (both making and reading) based on kinships with and celebrations of material and cultural worlds, rather than generalisations towards cartographic coherence. Must we be passive about these encodings? landuse=* could, in theory, easily be landuse=sacred_site or landuse=aboriginal_lands. There are projects across OSM that are attempting to map, articulate, reclaim or protect First Nations, Indigenous, or Aboriginal landsbut are continually stalled at the point of classification. One proposal, boundary=aboriginal_lands (Figure 4) makes one suggestion.

boundary=aboriginal_lands is a multi-perspective proposal. It provides two snapshots of the boundary, in almost oppositional duality. The first perspective is cartographic, as a "heavy dashed line," which might be imagined from above as a geopolitical tool designating different kinds of territorial claims. The second is as a terrestrial road sign, viewed from below, as a threshold is crossed between one person's land and another's. This duality between the 


\begin{tabular}{|c|c|}
\hline \multicolumn{2}{|c|}{ boundary=aboriginal_lands } \\
\hline Status: & Proposed (under way) \\
\hline \multicolumn{2}{|c|}{ Proposed by: Acrosscanadatrails } \\
\hline Tagging: & boundary=aboriginal_lands \\
\hline Applies to: & boundary \\
\hline Definition: & Tagging the boundary of aboriginal lands. \\
\hline \multicolumn{2}{|c|}{ Rendered as: heavy dashed line } \\
\hline Drafted on: & $2010-03-11$ \\
\hline RFC start: & $2008-06-25$ \\
\hline Vote start: & * \\
\hline Vote end: & * \\
\hline
\end{tabular}

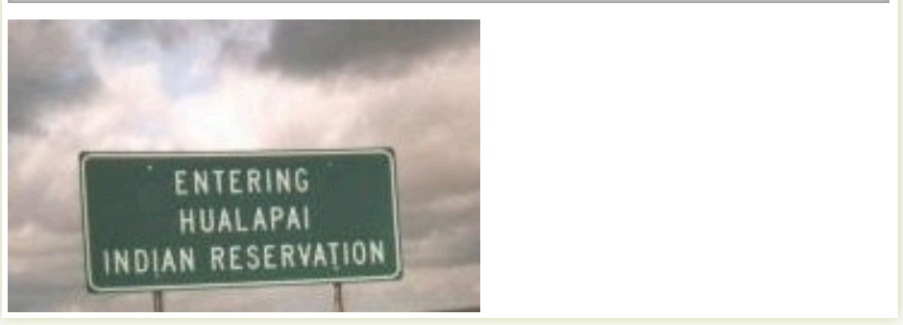

Figure 4. boundary=aboriginal_lands proposal by

Acrosscanadatrails.

top-down governmental and administrative understanding of what territory is, and a situated and local sense of ownership and lived experience is reflected throughout the proposal as a major impasse. It becomes translated into the difference between classifying land according to administrative levels (i.e., city, province, region) and governmental logics or being attentive to colonial presents and pasts, Aboriginal title claims, and First Nations' lived experiences. Throughout the discussion, tiptoeing around complex issues ensues, as subject and object are pushed and pulled apart, imagined kinships are inscribed into the conversation and present kinships ignored. Acrosscanadatrails, who made the intial proposal, writes:

"Suggestion: First Nations and Indian Reservations should be boundary=administrative; admin_level=1; border_type=first_nation; as they are international."

To this suggestion there is a series of responses, likening Aboriginal lands to national territories, national parks, international conglomerates, and nations without statehood. For instance:
"Should borders like this really be administrative? Certainly using admin_level=1 for this just looks wrong to me... --Eimai 17:22, 25 June 2008 (UTC)"

and

"It can also apply to other native people, such as the Masaai in Kenya/Tanzania or the Samii in Norway/Sweeden/Finland/Russia [sic]. boundary=native_reserve or boundary=native_nation is probably better. But I fully support removing them from boundary=administrative. Let admin_level=1 be reserved for supernational administrative borders such as the European union.--Skippern 13:15, 3 December 2008 (UTC)"

These conversations map the complex landscape of postcolonial geopolitics across the world against one simple question: is it possible to universalise the territorial conditions of Indigenous peoples and First Nations across the world under a single system of spatial classification? Eighteen months later, Acrosscanadatrails comes back with another attempt:

"All, ok how's this boundary=native_reserve; border_type $=$ territorial; place $=$ region; name $=$; admin_level=2 May be this should cover all grounds .--Acrosscanadatrails 12:37, 11 March 2010 (UTC)”

The conversation gets muddier. Skippern responds at 13:14 on 11 March 2010 (UTC) with a counter-proposal and some clarifications, arguing against the use of admin levels for reserves, for the broadening of place=region to place=region/country/city, and the inclusion of "description," as well as the reserve's "website” and/or Wikipedia article, its population, and "source=*." Two months later in May, Acrosscanadatrails revisits the proposal with a different suggestion—boundary: type=aboriginal_landsand renewed arguments for the administrative role of the boundary, this time further grounded in both terrain and territory, using contingent objects like signed treaties and checkpoints:

"admin_level=4-- because it has its own jurisdiction which is similar to a 'state/province' level, where it is still within a country 
(generally) more times than not. There are special cases (just like countries that are in transition \& dispute). In some countries there are signed agreements with members of each group

boundary=administrative -- because this is an 'administrative' boundary. Where it's known, and sometimes signed, as it would be trespassing if there is no implied visiting (there is no security check to go/through the area)

$\cdots$

--Acrosscanadatrails 16:02, 12 May 2010 (UTC)"

Here, the trouble of an ongoing social haunting erupts into the OSM platform through contingency (Bittner, Glasze, and Turk 2013). Effectively, the politics and processes of the classification reveal threads of tension between knowledges and unresolved colonialities. Significantly, it is the desire for universality in taxonomic structures that yields this conflict, as entanglements are often contradictory: is aboriginal_lands a use of the land, is it an ownership of the land, a territory, an administration? Or is it all of these things at once-or none of these things, depending on who is looking? Here, partial perspectives come into contact with one another, negotiating how and to what degree different realities translate and do not translate through the process of classification.

As the conversation continues, Hai-Etlik tries to map the structure of the Cowichan tribes against the administrative levels of the OSM classifications, and the structures of the Canadian state:

"I disagree, This would imply that, for instance, Cowichan 1 is not part of British Columbia and is a province in its own right. It doesn't even have its own government but is rather just one of 9 reserves in the Cowichan Tribes, and Cowichan Tribes as a whole is more comparable to a municipality in its scope than a province.

--Hai-Etlik 01:47, 1 July 2010 (UTC)”
Six years go by and the debate picks up again in November 2016, with others reflecting on previous posts with new spatial and temporal contexts. Warin61 argues that Aboriginal Lands get used for multiple purposes, and so the land_use tag would erase this diversity. Instead, the vote is cast to boundary=aboriginal lands, which "clearly sets this aside from other boundaries as it should be." Similarly, eighteen months later, this suggestion is supported by Arctic.gnome, who adds nuance to the debate over self-governance, with multiple levels suggested depending on which laws are followed.

The conversation on land_use=aboriginal_lands and boundary: type=aboriginal_lands continued for years, unresolved.

But this is not a wasted effort. The effort to pin down the clear systems of categorisation that comprise and structure our understanding of the world does important political work in revealing tensions, multiple perspectives, and the difficulty of generalising from, rather than paying heed to, situated knowledges. This is one of the major struggles within cartographic practice, and geographic information science more generally. Yet, rather than a cause for regret, this tension is productive: a dialogue across multiple spaces and times about how it is to be in and of the world.

\section{As Haraway writes:}

To see scientific knowledge as located and heterogeneous practice, which might (or might not) be "global" and "universal" in specific ways rooted in ongoing articulatory activities that are always potentially open to critical scrutiny from disparate perspectives, is to adopt the worldy stance of situated knowledges. (Haraway 2018, 138)

And so, such situated knowledges about how multiple boundaries and spatial realities overlap or co-exist in contradiction can indeed also be considered scientific knowledges about the lived realities of tensions between states and nations and peoples, about how land is used versus how it is owned, and what it means to look across the landscape rather than down from the sky. Furthermore, as Haraway $(2018,138)$ continues, "such knowledges are worth living for." 


\section{MAPPING-WITH: LIVING AND DYING}

Mapping neCESSARILY CONCEALS and illuminates, it necessarily creates trouble as it eliminates it. The critics of a universal science and a transcendental cartography are not wrong. We cannot fully relinquish the rules and logics of discourses that set the conditions of possibility for mapping, and counter-mapping, in the first place. To map is to engage a philosophy of representation, to at once reduce and extend the possibilities of the world through art, imagination, and science.

What role do we, as cartographers, play in the production of spaces around the world, and the mediation between the situated knowledges and god tricks between which we work? The tendrils of GPS traces span out across OSM (Figure 5).

Chthonic in their layers, and tentacular in their sprawl, I've always found this a far more interesting mapping, seeing the multitude of local practices, situated moments, and journeys across the earth. Less the domain of a universal science and more the residues of mappers as they trail from village to village, emerging with each new upload, this is not so much a map, as a mapping-with.

At the same time, staying with the trouble-for Haraway, at least - is not simply about the process of giving life to new growth. It is not against mathesis and taxinomia that such mappings emerge. The precisions of triangulation, the calculation of data, and the classification of spaces as they have emerged in these instances carry fascinating stories about the heterogeneity of life in this world. These practices are examples of ways in which we might stay with the trouble, and map-with cultures and landscapes and people; rather than against them, or in spite of them. They do not eschew the absenting power of the ghost or shadow, but rather they get comfortable with ambiguity and make room for the difficult and the uncomfortable, the heterogenous, the unexpected, and the unorthodox to persist in shaping pasts, presents, and futures. Abandoned, or closed, or still under discussion-the trouble does not disappear. Rather, it lingers and haunts, either on servers, or landscapes, or lives.

What might mapping-with look like? This has been a largely theoretical rather than empirical argument. However, just as the making of maps might inform how we think about them, so too can thinking about maps inform how we make them. Haraway draws a critical distinction between those who simply watch and those who harness a critical reflexivity (rather than polemic extremes) to become modest witnesses of the technical and technological shifts that take place:

So I close this evocation of the figure of the modest witness in the narrative of science with the hope that technologies for establishing what may count as the case about the world may be rebuilt to bring the technical and the political back into realignment so that questions about possible livable worlds lie visibly at the heart of our best science. (Haraway 2018, 38)

In short, do we simply watch-or map-with the categories that we have, or can we embrace new roles as modest witnesses who are more interested in mapping-with, rather than mapping-to, mapping-for, or mapping-because. This is a kind of "response-ability" (Haraway 2016), an ethics that does not sit with the lone cartographer staring at a screen, but rather asks us to acknowledge the collective spaces that we inhabit, and to take care in their construction.

So, while "mapping-with" may currently be a political fiction, there is ample room for potential in the practice of cartographic science to make new categories, create new starting points or redefine what classification is altogether. On a platform like OSM, there has always been opportunity for political as well as practical intervention into the

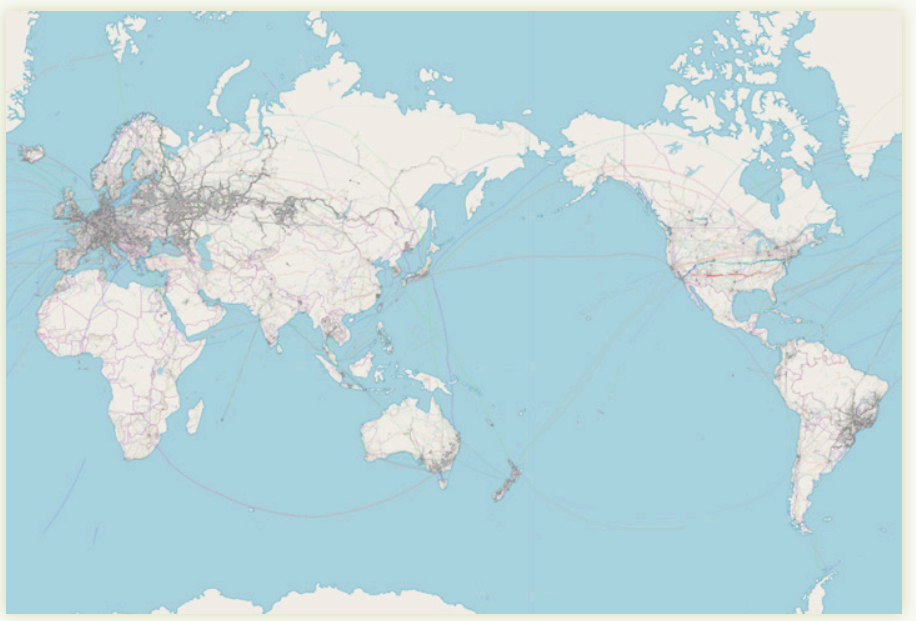

Figure 5. Mapping-with: a cartographic chthulucene? Public GPS Traces on OSM (June 2, 2019). 
work that cartography does: why should hop fields, villages, and Indigenous lands not have been the starting point for our classificatory systems, rather than fitting them into structures that currently exist? If we make mappings that start from landscapes and people and histories, rather than cartographies, classifications, and computers, it might it be possible to take pleasure in the confusions that mappings bring, and put them to political use. This is the beginning, not the end, of a critical and empirical project that seeks to reengage the classificatory logics and politics of geographic information systems toward different futures. This project is a cyborg cartography that has irreverence for its predecessors in Western epistemologies and is "about lived social and material worlds in which people are not afraid of their kinships with animals and machines, not afraid of permanently partial identities and contradictory standpoints" (Haraway 1985, 72).

And so mapping-with is also about the "relations between life and death" (Haraway 2016, 8): the process of living is also a process of dying. If mapping is the making of worlds, then it is also the unmaking of them. As mappers who are modest witnesses, we cannot be removed from the trouble. Our bodies, as well as our lines, our numbers, our categories, and our knowledges are entangled, mapping-with and unmapping-with. What worlds can we unmake, what boundaries can we erase, what landscapes can we rename from the partial rather than the top-down? In the compost of erasing lines as well as making them, new species flourish. Dying with our mapping is accepting the uncertainty, and the ambiguity, and asking our mappings to be more turbulent and situated. It is also a reconciliation between mathesis and taxinomia and those upon whom they have inflicted traumas. Where once they lent their power to an absolutism or a universality, or a top-down representation that demanded unflinching obedience, they might work up and demand the same from the top, in refusing to re-categorise, regulate, to homogenise.

I have argued that the tensions, translations, and comparisons produced through processes of cartographic classification offer new pathways for engaging mapping as a political, world-building tool. Rather than simply eliding or critiquing classification-one of the cornerstones of cartography since the nineteenth century-embracing it as fundamental to mapping processes and as a conceptual tool of possibility may open up alternative and radical-but also useful-ways of thinking about spaces, politics, landscapes, and environments. Within the case of OpenStreetMap, reencountering feature proposals from the perspective of Donna Haraway, it is clear that already these possibilities are being charted within the mapping structures-from international conversations about what kind of place a hop field is, to whether homes or villages should be mapped at all, to the ideological and assumptive problems of state ownership vs. First Nations ownership inherent in and inherited by the spatial classificatory systems that we use. So, I propose moving our classificatory fix-points, models, and assumptions away from the generalised to the troubled, to the graveyard of lost proposed features and changesets, and dying there, in the hope of fertilising new possibilities. Mapping-with, rather than against, the oddkin proposals set out between people, landscapes, and pasts, perhaps ignored allies will help by adding ambivalence and fuzziness, to our mappings, composting with situated knowledges, and embracing the chthonic-in cooperation, rather than subservience or domination.

\section{REFERENCES}

Barad, Karen. 2007. Meeting the Universe Halfway: Quantum Physics and the Entanglement of Matter and Meaning. Durham, NC: Duke University Press.

Bittner, Christian, Georg Glasze, and Cate Turk. 2013. "Tracing Contingencies: Analyzing the Political in Assemblages of Web 2.0 Cartographies." GeoJournal 78 (6): 935-948. doi: 10.1007/s10708-013-9488-8.

Borges, Jorge Luis. 1964. Other Inquisitions: 1937-1952. Translated by Ruth Simms. New York: Washington Square Press.
Cidell, Julie. 2008. "Challenging the Contours: Critical Cartography, Local Knowledge and the Public." Environment and Planning A 40 (5): 1202-1218.

Counter Cartographies Collective, Craig Dalton, and Liz Mason-Deese. 2012. "Counter(mapping) Actions: Mapping as Militant Research.” ACME 11 (3): 439-466.

Crampton, Jeremy. 2011. "Cartographic Calculations of Territory.” Progress in Human Geography 35 (1): 92-103. doi: 10.1177/0309132509358474. 
Del Casino, Vincent, and Matthew Hannah. 2005.

"Beyond the 'Binaries': A Methodological Intervention for Interrogating Maps as Representational Practices." ACME 4 (1): 34-56.

Elwood, Sarah. 2006. "Negotiating Knowledge Production: The Everyday Inclusions, Exclusions, and Contradictions of Participatory GIS Research.” The Professional Geographer 58 (2): 197-208. doi: 10.1111/j.1467-9272.2006.00526.x.

. 2008. "Volunteered Geographic Information: Future Research Directions Motivated by Critical, Participatory and Feminist GIS.” GeoJournal 72 (3/4): 173-183. doi: 10.1007/s10708-008-9186-0.

Elwood, Sarah, and Agnieszka Leszczynski. 2013. "New Spatial Media, New Knowledge Politics.” Transactions of the Institute of British Geographers 38 (1): 544-559. doi: 10.1111/j.1475-5661.2012.00543.x.

Foucault, Michel. 2002. The Order of Things. Translated by Alan Sheridan. London: Routledge.

\section{- 2003. "Society Must Be Defended": Lectures at the}

Collège de France, 1975-76. Translated by David Macey. Edited by Mario Bertani and Alessandro Fontana. New York: Picador.

Gekker, Alex. 2016. Uniquitous Cartography: Casual Power in Digital Maps. PhD diss. Utrecht University. https:// dspace.library.uu.nl/handle/1874/344172.

Gerlach, Joe. 2010. "Vernacular mapping, and the Ethics of What Comes Next." Cartographica 45 (3): 165-168. doi: 10.3138/carto.45.3.165.

2015. "Editing Worlds: Participatory Mapping and a Minor Geopolitics." Transactions of the Institute of British Geographers 40 (2): 273-286. doi: 10.1111/ tran.12075.

Giesking, Jen Jack. 2018. “Operating Anew: Queering GIS with Good Enough Software.” The Canadian Geographer 62 (1): 55-66. doi: 10.1111/cag.12397.
Glasze, Georg, and Chris Perkins. 2015. "Social and Political Dimension of the OpenStreetMap Project: Towards a Critical Geographical Research Agenda." In OpenStreetMap in GIScience, edited by Jamal Jokar Arnsanjani, Alexander Zipf, Peter Mooney and Marco Helbich, 143-166. Heidelberg: Springer Verlag. doi: 0.1007/978-3-319-14280-7_8.

Goodchild, Michael. 2009. "Neogeography and the Nature of Geographic Expertise." Journal of Location-Based Services 3 (2): 82-96. doi: 10.1080/17489720902950374.

Gordon, Avery. 2008. Ghostly Matters: Haunting and the Sociological Imagination. Minneapolis, London: University of Minnesota Press.

Guttenberg, Albert. 1982. "How to Crowd and Still be Kind-the Dutch Woonerf." Humboldt Journal of Social Relations 9 (2): 100-119.

Haklay, Muki. 2013. "Neogeography and the Delusion of Democratisation." Environment and Planning A 45 (1): 55-69. doi: 10.1068/a45184.

Haraway, Donna. 1985. "A Manifesto for Cyborgs: Science, Technology, and Socialist Feminism in the 1980s.” Socialist Review 15 (2): 65-107.

1988. "Situated Knowledges: The Science Question in Feminism and the Privilege of Partial Perspective." Feminist Studies 14 (3): 575-599. doi: $10.2307 / 3178066$.

. 2016. Staying with the Trouble: Making Kin in the Cthulucene. Durham, NC: Duke University Press.

_.2018.Modest_Witness@Second_Millenium. FemaleMan@_Meets_OncoMouse: Feminism and Technoscience, Second Edition. London: Routledge.

Kwan, Mei-Po. 2002. "Feminist Visualization: Re-envisioning GIS as a Method in Feminist Geographic Research." Annals of the Association of Amercian Geographers 92 (4): 645-661. doi: 10.1111/1467-8306.00309.

2007. "Affecting Geospatial Technologies: Toward a Feminist Politics of Emotion." The Professional Geographer 59 (1): 22-34. doi: 10.1111/j.1467-9272.2007.00588.x. 
Lammes, Sybille. 2017. "Digital Mapping Interfaces: From Immutable Mobiles to Mutable Images." New Media E Society 19 (7): 1019-1033. doi: 10.1177/1461444815625920.

Leszczynski, Agnieszka. 2009. "Poststructuralism and GIS: Is There a 'Disconnect'?" Environment and Planning D 27 (4): 581-602. doi: 10.1068/d1607.

Leszczynski, Agnieszka, and Sarah Elwood. 2015. "Feminist Geographies of New Spatial Media." The Canadian Geographer 59 (1): 12-28. doi: 10.1111/ cag.12093.

Lin, Wen. 2013. "Situating Performative Neogeography: Tracing, Mapping, and Performing 'Everyone's East Lake.” Environment and Planning A 45 (1): 37-54. doi: 10.1068/a45161.

Liu, Sophia B., and Leysia Palen. 2010. “The New Cartographers: Crisis Map Mashups and the Emergence of Neogeographic Practice." Cartography and Geographic Information Science 37 (1): 69-90. doi: 10.1559/152304010790588098.

Massey, Doreen. 2005. For Space. London: Sage.

McHaffie, Patrick. 2000. "Surfaces: Tacit Knowledge, Formal Language, and Metaphor at the Harvard Lab for Computer Graphics." International Journal of Geographic Information Science 14: 755-773. doi: 10.1080/136588100750022778.

Merriman, Peter. 2007. Driving Spaces: A Culturalhistorical Geography of England's M1 Motorway. RGSIBG Book Series. Oxford, UK: Blackwell.

OpenStreetMap Wiki. n.d. Accessed December 22, 2017. https://wiki.openstreetmap.org.

O’Sullivan, David. 2006. "Geographical Information Science: Critical GIS.” Progress in Human Geography 30 (6): 783-791. doi: 10.1177/0309132506071528.
Pavlovskaya, Marianna. 2018. "Critical GIS as a Tool for Social Transformation." The Canadian Geographer 62 (1): 40-54. doi: 10.1111/cag.12438.

Peluso, Nancy Lee. 1995. "Whose Woods are These? Counter-mapping Forest Territories in Kalimantan, Indonesia." Antipode 27 (4): 383-406. doi: j.14678330.1995.tb00286.x.

Perkins, Chris. 2014. "Plotting Practices and Politics: (Im)mutable Narratives in OpenStreetMap." Transactions of the Institute of British Geographers 39 (2): 304-317. doi: 10.1111/tran.12022.

Pickles, John. 2004. A History of Spaces: Cartographic Reason, Mapping, and the Geo-coded World. New York: Routledge.

Ryan, Simon. 1996. The Cartographic Eye: How Explorers Saw Australia. Cambridge: Cambridge University Press.

Thatcher, Jim, and Laura Beltz Imaoka. 2018. "The Poverty of GIS Theory: Continuing the Debates around the Political Economy of GISystems." The Canadian Geographer 62 (1): 27-34. doi: 10.1111/ cag.12437.

Wilmott, Clancy. 2016. "Small Moments in Spatial Big Data: Calculability, Authority and Interoperability in Everyday Mobile Mapping." Big Data and Society. 3 (2): doi: 10.1177/2053951716661364.

Wilson, Matthew. 2011. “'Training the Eye': Formation of the Geocoding Subject." Social \& Cultural Geography 12 (4): 357-376. doi: 10.1080/14649365.2010.521856.

2017. New Lines: Critical GIS and the Trouble of the Map. Minneapolis, MN: University of Minnesota Press. doi: 10.5749/j.ctt1pwt6q4. 